\title{
Zeaxanthin Induces Apoptosis via ROS-Regulated MAPK and AKT Signaling Pathway in Human Gastric Cancer Cells
}

\author{
Ya-Nan Sheng $\mathbb{1 D}^{1, *}$ \\ Ying-Hua Luo ${ }^{2, *}$ \\ Shao-Bin $\mathrm{Liu}^{3, *}$ \\ Wan-Ting $X u^{3}$ \\ Yu Zhang ${ }^{3}$ \\ Tong Zhang ${ }^{3}$ \\ Hui Xue ${ }^{3}$ \\ Wen-Bo Zuo ${ }^{3}$ \\ Yan-Nan Li $\mathbb{D}^{3}$ \\ Chang-Yuan Wang ${ }^{1,4}$ \\ Cheng-Hao Jin ${ }^{1,3,4}$
}

'Department of Food Science and Engineering, College of Food Science, Heilongjiang Bayi Agricultural University, Daqing 163319, People's Republic of China; ${ }^{2}$ Department of Grass Science, College of Animal Science \& Veterinary Medicine, Heilongjiang Bayi Agricultural University, Daqing 163319, People's Republic of China; ${ }^{3}$ Department of Biochemistry and Molecular Biology, College of Life Science \& Technology, Heilongjiang Bayi Agricultural University, Daqing 163319, People's Republic of China; ${ }^{4}$ National Coarse Cereals Engineering Research Center, Daqing 163319, People's Republic of China

*These authors contributed equally to this work

Correspondence: Cheng-Hao Jin; Chang-Yuan Wang

Department of Food Science and Engineering, College of Food Science, Heilongjiang Bayi Agricultural University, Daqing 163319, People's Republic of

China

Tel +86 13351747387;

+86 I383696। 288

Email jinchenghao3727@qq.com;

2633204897@qq.com
This article was published in the following Dove Press journal: OncoTargets and Therapy

Background: Zeaxanthin, a carotenoid commonly found in plants, has a variety of biological functions including anti-cancer activity.

Purpose: This study aimed to investigate the potential mechanisms of zeaxanthin in human gastric cancer cells.

Methods: CCK-8 assay was used to examine the cytotoxic effect of zeaxanthin on human gastric cancer cells. Flow cytometry was used to analyse AGS cell cycle distribution and apoptosis status. Western blot analysis was used to detect the expression levels of cyclerelated proteins (Cyclin A, Cyclin B1, CDK1/2, p21, and p27), apoptosis-related proteins (Bcl-2, Bad, caspase-3, PARP), MAPK, AKT, STAT3, and NF-кB.

Results: CCK- 8 assay showed that zeaxanthin has obvious cytotoxic effects on 12 types of human gastric cancer cells, but no obvious toxic effect on normal cells. In addition, flow cytometry and Western blotting results showed that zeaxanthin induces apoptosis by reducing mitochondrial membrane potential; increasing Cytochrome $\mathrm{C}$, Bax, cleaved-caspase-3 (clecas-3), and cleaved-PARP (cle-PARP) expression levels; and decreasing Bcl-2, pro-caspase-3 (pro-cas-3), and pro-PARP expression levels. Additionally, zeaxanthin caused cell cycle arrest at the G2/M phase by increasing the levels of p21 and p27 and reduced the levels of AKT, Cyclin A, Cyclin B1, and Cyclin-dependent kinase 1/2 (CDK1/2). Furthermore, after zeaxanthin treatment, the expression levels of reactive oxygen species (ROS), p-JNK, p-p38, and $\mathrm{I}-\kappa \mathrm{B}$ increased, and the expression levels of p-ERK, p-AKT, STAT3, and NF- $\kappa \mathrm{B}$ decreased. However, the ROS scavenger N-acetylcysteine (NAC) and MAPK inhibitors inhibited zeaxanthin-induced apoptosis, and under the action of zeaxanthin, MAPK regulated $\mathrm{NF}-\kappa \mathrm{B}$ and STAT3, and reduced their protein expression levels.

Conclusion: Zeaxanthin has a potential effect against gastric cancer cells through the ROSmediated MAPK, AKT, NF- $\mathrm{BB}$, and STAT3 signaling pathways, and it is expected to become a new drug for the treatment of human gastric cancer.

Keywords: zeaxanthin, ROS, gastric cancer, apoptosis, cell cycle arrest

\section{Introduction}

Gastric cancer is a major health problem and one of the most common malignant tumours of the digestive system. ${ }^{1}$ Although the incidence of gastric cancer has been declining for many years, it is the fifth highest among all cancers. ${ }^{2}$ In addition, gastric cancer has a high mortality rate worldwide and it is the third leading cause of tumour death. ${ }^{3}$ As the early detection of gastric cancer is difficult, opportunities for surgical resection are lost. For advanced gastric cancer, the choice of drugs 
largely determines their therapeutic effect. ${ }^{1}$ Therefore, the development of new and efficient drugs with low toxicity and side effects are necessary.

Apoptosis is an orderly and programmed cell death process, ${ }^{4}$ which maintains the normal development of organisms by removing unviable cells. ${ }^{5}$ Mitochondria play a key role in activating apoptosis in cells, and a reduction in the mitochondrial membrane potential results in the release of apoptotic factors. ${ }^{6}$ For example, the regulation of anti-apoptotic and pro-apoptotic members of the Bcl-2 family leads to the release of cytochrome $\mathrm{C}$ into the cytoplasm and the formation of apoptotic bodies through caspase activation. ${ }^{4,7}$ Caspase- 3 is a downstream executor of apoptosis and plays a key role in the apoptotic process. ${ }^{8}$ Pro-cas-3 is cleaved to produce active cle-cas- 3 , and cle-cas- 3 induces the cleavage of pro-PARP to produce cle-PARP, which causes apoptosis. ${ }^{9}$

Cancer cell survival, differentiation, and movement are associated with different intracellular signaling pathways, such as the MAPK and AKT pathways. Mitogen-activated protein kinase (MAPK) family members, including extracellular signal-regulated protein kinase (ERK), c-Jun N-terminal protein kinase (JNK), and p38 MAPK are crucial for the maintenance of cells. ${ }^{10,11}$ Activated JNK and p38 MAPK induce apoptosis, and phosphorylated ERK promotes cell survival. ${ }^{12}$ MAPKs cause apoptosis through the down-regulation of NF- $\mathrm{KB}$, which is an inducible transcription factor and involved in cell survival, cell adhesion, inflammation, differentiation, and growth. ${ }^{13}$ AKT is a serine/threonine protein kinase that can phosphorylate multiple proteins and plays an important role in regulating cell survival. ${ }^{14}$ Studies have shown that the AKT and MAPK signals pathways inhibit the STAT3 pathway in melanoma-derived cell lines. ${ }^{15}$

Reactive oxygen species (ROS), including superoxide anions, hydrogen peroxide, and hydroxyl radicals are generated in mitochondria and used as intermediates for signal transmission. ${ }^{16}$ Production of ROS is one of the mechanisms used to kill tumour cells. ${ }^{12}$ Several studies have shown that the accumulation of ROS can activate the MAPK and AKT pathways, resulting in cell apoptosis. ${ }^{17,18}$

Zeaxanthin is an oxidized carotenoid, ${ }^{19}$ mainly found in dark green vegetables, egg yolks, corn, and citrus fruits. ${ }^{20}$ Zeaxanthin shows potential anti-inflammatory and anticancer effects. ${ }^{21-23}$ Although some studies have shown that zeaxanthin is effective against breast cancer, bladder cancer, and uveal melanoma cells, its specific mechanism and role in human gastric cancer have not been explored. ${ }^{24-26}$

\section{Materials and Methods \\ Chemicals and Reagents}

Zeaxanthin (Solarbio, Beijing, China) and 5-fluorouracil (5FU) (Med Chem Express, Princeton, NJ, USA) wa dissolved in $100 \%$ dimethylsulfoxide (DMSO) to prepare a stock solution of $20 \mathrm{mM}$ concentration, and stored at $-20^{\circ} \mathrm{C}$. Other chemicals used in the study were of analytical grade.

\section{Cell Culture}

Twelve types of human gastric cancer cells: AGS, KATO-3, MKN-28, MKN-45, NCI-N87, YCC-1, YCC-6, YCC-16, SUN-5, SUN-216, SUN-484, SUN-668, and normal lung fibroblasts IMR-90 cells were purchased from the American Type Culture Collection (ATCC, Manassas, VA, USA). L-02 normal liver cells, GES-1 normal gastric epithelial mucosal cells, and the human embryonic kidney 293T cells were purchased from Saiqi Biotech Co., Ltd. (Shanghai, China). Cells were cultured at $37^{\circ} \mathrm{C}$ and the carbon dioxide content was $5 \%$. All cells were cultured in DMEM or RPMI-1640 medium supplemented with $10 \%$ Foetal Bovine Serum (FBS), penicillin $(100 \mathrm{U} / \mathrm{mL})$ and streptomycin $(100 \mu \mathrm{g} / \mathrm{mL}$; Gibco $) .{ }^{27}$

\section{Cell Viability Assay}

Cells were seeded into 96-well plates at a density of $1 \times 10^{4}$ cells/well at a temperature of $37^{\circ} \mathrm{C}$ and a carbon dioxide content of 5\%. Zeaxanthin was added to the cells at concentrations of $1,3,10,30$, and $100 \mu \mathrm{M}$ for $24 \mathrm{~h}$, or they were treated with zeaxanthin $\left(17 \mu \mathrm{M}\right.$, the $\mathrm{IC}_{50}$ value $)$ for 3 , $6,12,24$, and $36 \mathrm{~h}$. Ten micro-litres of Cell Counting Kit8 (CCK-8) reagent (Solarbio) was added and after $2 \mathrm{~h}$, and samples were examined using a microplate reader (BioTek, Instruments Inc., Winooski, VT, USA). Optical density (OD) values were recorded at $450 \mathrm{~nm}$ to determine the percentage of viable cells. The percentage of cell viability was calculated at $50 \%$ inhibitory concentration $\left(\mathrm{IC}_{50}\right)$ using Graphpad Prism 5 software (GraphPad Software, Inc., La Jolla, CA, USA). ${ }^{28}$ All experiments and measurements were performed in triplicate.

\section{Cell Apoptosis Analysis}

The effect of zeaxanthin on AGS cells was analysed using Annexin V-fluorescein isothiocyanate (FITC)/PI double staining and Hoechst 33324 (Beyotime Biotechnology Institute) staining. Cells were seeded into 6-well plates at a density of 
$1 \times 10^{5}$ cells/well for $24 \mathrm{~h}$, and treated with $17 \mu \mathrm{M}$ zeaxanthin and 5-FU for 3, 6, 12, and $24 \mathrm{~h}$. Cells were collected and washed with $500 \mu \mathrm{L}$ PBS. A mitochondrial membrane potential assay kit (Solarbio) was used to detect mitochondrial membrane potential. The treated cells were resuspended in culture medium and JC-1, and maintained in a $37{ }^{\circ} \mathrm{C}$ water bath for $20 \mathrm{~min}$ in the dark. Annexin V-fluorescein isothiocyanate (FITC)/PI (Beyotime Biotechnology Institute) was used to detect apoptosis. Treated cells were resuspended in $195 \mu \mathrm{L}$ Binding Buffer, then $3 \mu \mathrm{L}$ Annexin V-FITC was added in the dark for $5 \mathrm{~min}$, and finally $2 \mu \mathrm{L}$ PI was added in the dark for $10 \mathrm{~min}$. Hoechst 33324/PI was used for the cell double staining experiments. After the drug-treated cells were washed with PBS 2-3 times, $195 \mu \mathrm{L}$ Binding Buffer, $3 \mu \mathrm{L}$ Hoechst 33324, and $2 \mu \mathrm{L}$ PI were added for $5 \mathrm{~min}$. Cells were analysed using the EVOS FL Automated Cell Imaging System (Thermo Fisher Scientific, Inc., Waltham, MA, USA) and flow cytometry (Beckman Coulter, Inc., Brea, CA, USA). ${ }^{29}$

\section{Cell Cycle Analysis}

Cells were seeded into 6-well plates at a density of $1 \times 10^{5}$ cells/well for $24 \mathrm{~h}$, after treatment of AGS cells with 17 $\mu \mathrm{M}$ zeaxanthin for $3,6,12$, and $24 \mathrm{~h}$. Pre-cooled $70 \%$ ethanol was used to fix the cells at $-20{ }^{\circ} \mathrm{C}$ for $12 \mathrm{~h}$, followed by washing twice with $500 \mu \mathrm{L}$ PBS. The cells were resuspended in $100 \mu \mathrm{L}$ RNase A at $37^{\circ} \mathrm{C}$ for $30 \mathrm{~min}$, and then stained with $400 \mu \mathrm{L}$ PI at $4{ }^{\circ} \mathrm{C}$ for $30 \mathrm{~min}$ in the dark. The cells were then analysed by flow cytometry. ${ }^{30}$

\section{Measurement of ROS Generation}

Cells were seeded in 6 -well plates $\left(1 \times 10^{5}\right.$ cells/well $)$ and incubated for $24 \mathrm{~h}$ in a cell culture incubator, followed by treatment with $17 \mu \mathrm{M}$ zeaxanthin for 3, 6, 12, and $24 \mathrm{~h}$. Intracellular ROS generation was detected using the oxidation-sensitive fluorochrome probe DCFH-DA. The cells were harvested and incubated with DCFH-DA at $37{ }^{\circ} \mathrm{C}$ for $30 \mathrm{~min}$ in the dark. In separate experiments, cells were pre-treated with the ROS inhibitor NAC for $2 \mathrm{~h}$ and then treated with zeaxanthin for $24 \mathrm{~h}$. Intracellular ROS levels were measured using the EVOS FL Automated Cell Imaging System (Thermo Fisher Scientific, Inc.). ${ }^{31}$

\section{Western Blot Analysis}

After culturing the cells for $24 \mathrm{~h}$, the zeaxanthin group was treated with zeaxanthin for $24 \mathrm{~h}$, then harvested; the zeaxanthin and inhibitor groups were treated with ERK (FR180204), JNK (SP600125), p38 (SB203580) inhibitor, or NAC for $2 \mathrm{~h}$, treated with zeaxanthin for $24 \mathrm{~h}$, and then harvested; the inhibitor group was treated with FR180204, SP600125, SB203580, or NAC for $24 \mathrm{~h}$, then harvested. Cells were lysed in lysis buffer for $30 \mathrm{~min}$, and cell lysates were centrifuged at $12,000 \mathrm{rpm}$ for $30 \mathrm{~min}$ at $4{ }^{\circ} \mathrm{C}$. Proteins were dissolved in $10 \%$ or $12 \%$ sodium dodecyl sulphate polyacrylamide gel electrophoresis, transferred to a nitrocellulose membrane, and blocked for $2 \mathrm{~h}$ in $5 \%$ skimmed milk at room temperature. The membrane was washed and incubated with primary antibody (Santa Cruz Biotechnology Co., Dallas, TX, USA) at $4{ }^{\circ} \mathrm{C}$ for $12 \mathrm{~h}$. Protein measurements were performed using an enhanced chemiluminescence kit (Thermo Fisher Scientific, Inc.) and an Amersham Imager 600 (GE, Fairfield, Connecticut, United States). ${ }^{32}$

\section{Statistical Analysis}

All experiments were performed in triplicate, and the obtained data were represented as means \pm standard error. The data were analysed by one-way analysis of variance followed by Tukey's post hoc tests using SPSS version 21.0 statistical software. Significance was determined at $* p<0.05,{ }^{* *} p<0.01$, or $* * * p<0.001$.

\section{Results}

\section{Zeaxanthin Inhibits the Proliferation of Gastric Cancer Cells}

As shown in Figure 1A, zeaxanthin significantly inhibited the activity of gastric cancer cells in a concentration-dependent manner compared with 5-FU. The $\mathrm{IC}_{50}$ values of zeaxanthin and 5-FU were calculated and are shown in Figure 1B. In addition, the results show that zeaxanthin significantly inhibited the activity of gastric cancer cells in a time-dependent manner compared with that by 5 -FU. Figure $1 \mathrm{C}$ and $\mathrm{D}$ show that zeaxanthin has lower toxicity in normal human cells than that does 5-FU. Furthermore, it was found that zeaxanthin showed the best inhibitory effects on AGS cells, with $\mathrm{IC}_{50}$ values of zeaxanthin and 5-FU on AGS cells were $17 \mu \mathrm{M}$ and $23.34 \mu \mathrm{M}$, respectively. These results show that zeaxanthin has good inhibitory effects on gastric cancer cells, and its toxicity and side effects are lower than those of 5-FU. Furthermore, AGS cells showed the most sensitivity in the above experiments; therefore, they were selected for subsequent experiments.

\section{Zeaxanthin Induces Apoptosis in AGS Cells}

As shown in Figure 2A, the fluorescence intensity of Hoechst 33342 and PI gradually increased as the treatment 
A

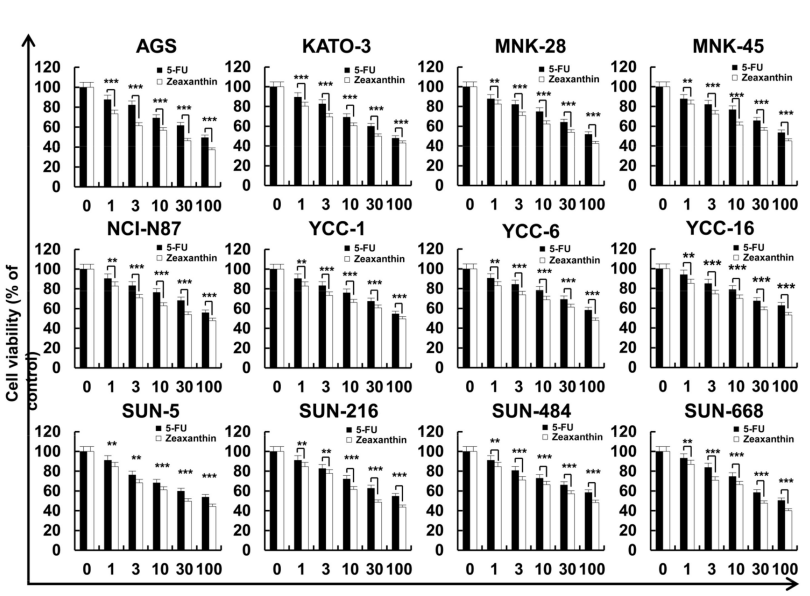

C

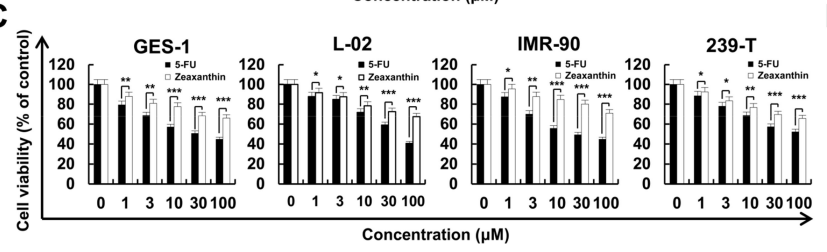

B
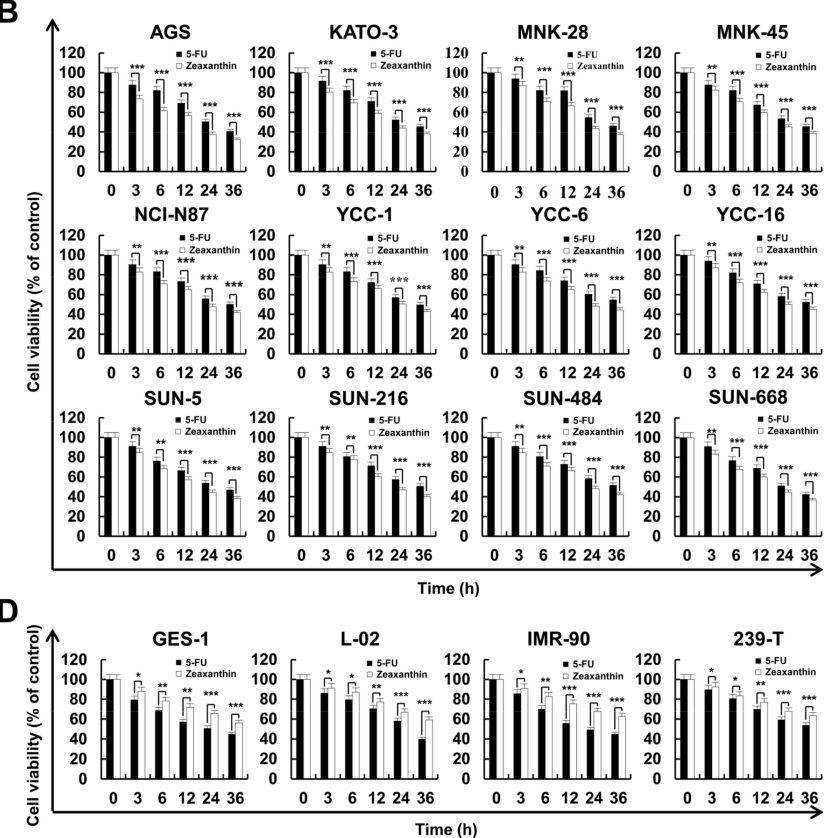

Figure I Cytotoxic effect of zeaxanthin on human gastric cancer cells. (A) Twelve human gastric cancer cell lines were treated with zeaxanthin and 5-FU at doses of I, 3, I0, 30 , and $100 \mu \mathrm{M}$ for $24 \mathrm{~h}$, after which their cell viabilities were determined by CCK-8 assay. (B) I 2 human gastric cancer cell lines were treated for 3, 6, I2, 24, and $36 \mathrm{~h}$ with the $I_{50}$ value of zeaxanthin and 5-FU, after which their cell viabilities were determined by CCK-8 assay. (C) GES-I, L-02, IMR-90, and 239-T cells were treated with zeaxanthin and 5-FU at doses of I, 3, I0, 30, and I00 $\mathrm{MM}$ for $24 \mathrm{~h}$, after which their cell viabilities were determined by CCK-8 assay. (D) GES-I, L-02, IMR-90, and 239-T cells were treated for $3,6,12,24$, and $36 \mathrm{~h}$ with the $\mathrm{IC}_{50}$ value of zeaxanthin and 5 -FU, after which their cell viabilities were determined by CCK-8 assay. ${ }^{*} p<0.05$, $* * p<0.0 \mathrm{I}$, $* * * p<0.001$ vs the control group.

time increased. In addition, apoptosis of AGS cells under zeaxanthin treatment was significantly greater than that in the 5-FU group. Besides, early and late cell apoptosis were also tested by flow cytometry. As shown in Figure 2B, the apoptosis rates of zeaxanthin and 5-FU treated cells were $56.36 \%$ and $42.67 \%$ after $24 \mathrm{~h}$ of treatment, respectively. As shown in Figure 2C, zeaxanthin significantly reduced the mitochondrial membrane potential (MMP). In addition, related apoptotic proteins were studied by Western blot analysis. As shown in Figure 2D, the expression levels of Bax, Cytochrome C, cle-cas-3, and cle-PARP increased, while the expression levels of Bcl-2, pro-cas-3, and proPARP proteins significantly decreased. The results indicate that zeaxanthin could induce apoptosis through the mitochondrial pathway.

\section{Zeaxanthin Activates MAPK Signaling Pathways in AGS Cells}

As shown in Figure 3, under zeaxanthin treatment, protein expression levels of phosphorylated $\mathrm{p} 38$, JNK, and I- $\mathrm{KB}$ increased as the treatment time increased, while protein expression levels of phosphorylated ERK, STAT3, and NF- $\kappa B$ decreased. As shown in Figure 4A, compared with the untreated group, the protein expression levels of
p-ERK, p-STAT3, NF- $\kappa B, B c l-2$, and pro-cas-3 in the zeaxanthin group were significantly reduced, while the protein expression levels of I- $\mathrm{kB}$ and cle-cas-3 were significantly increased. Compared with the zeaxanthin group, the protein expression levels of p-ERK, p-STAT3, NF- $\kappa B$, and Bcl-2 in the zeaxanthin and FR180204 groups were significantly reduced, while the protein expression levels of I- $\mathrm{kB}$, pro-cas-3, and cle-cas-3 were significantly increased. Compared with the untreated group, the protein expression levels of p-ERK, p-STAT3, NF-kB, Bcl-2, $\mathrm{I}-\mathrm{KB}$, and pro-cas-3 in the FR180204 groups were significantly reduced, while the protein expression level of clecas-3 significantly increased. As shown in Figure 4B and $\mathrm{C}$, compared with the untreated group, the protein expression levels of p-JNK, p-p38, I- $\mathrm{BB}$ and cle-cas-3 in the zeaxanthin group significantly increased, while the protein expression levels of p-STAT3, NF- $\mathrm{KB}, \mathrm{Bcl}-2$, and pro-cas3 significantly reduced. Compared with the zeaxanthin group, the protein expression levels of $\mathrm{p}-\mathrm{JNK}, \mathrm{I}-\mathrm{kB}, \mathrm{Bcl}-$ 2 , and cle-cas-3 in the zeaxanthin and SP600125 groups significantly reduced, while the protein expression levels of p-STAT3, NF- $\kappa \mathrm{B}$, and pro-cas-3 significantly increased. Compared with the zeaxanthin group, the protein expression levels of p-p38, I-kB, Bcl-2, and cle-cas-3 in the 
A
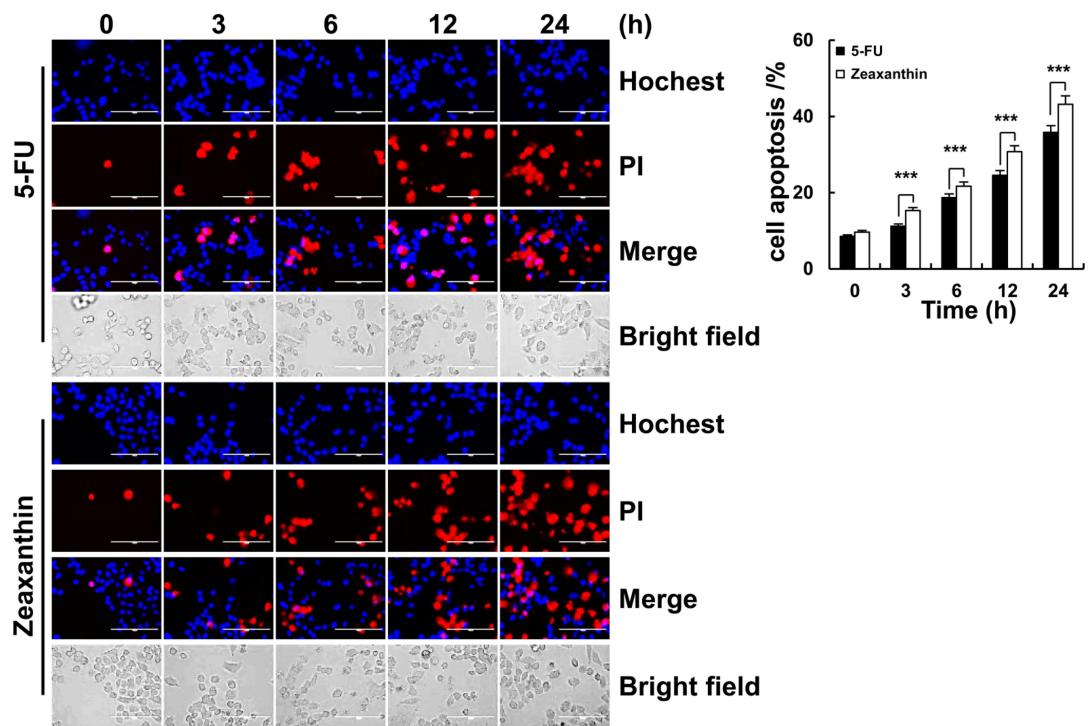

B

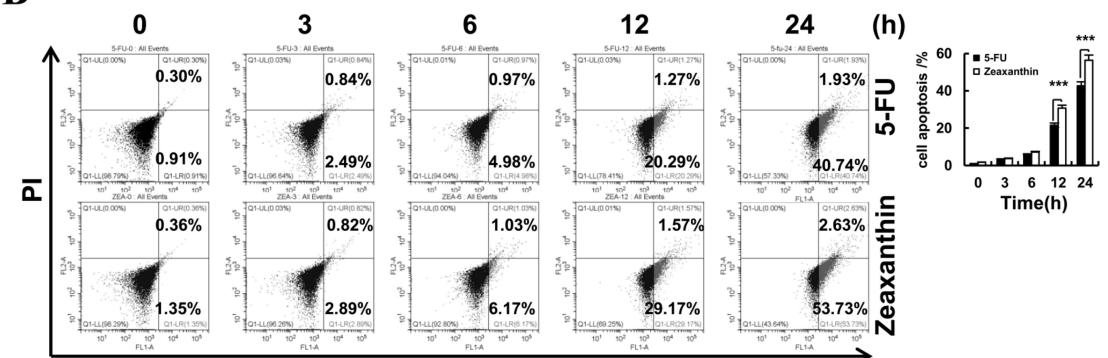

C

Annexin V-FITC
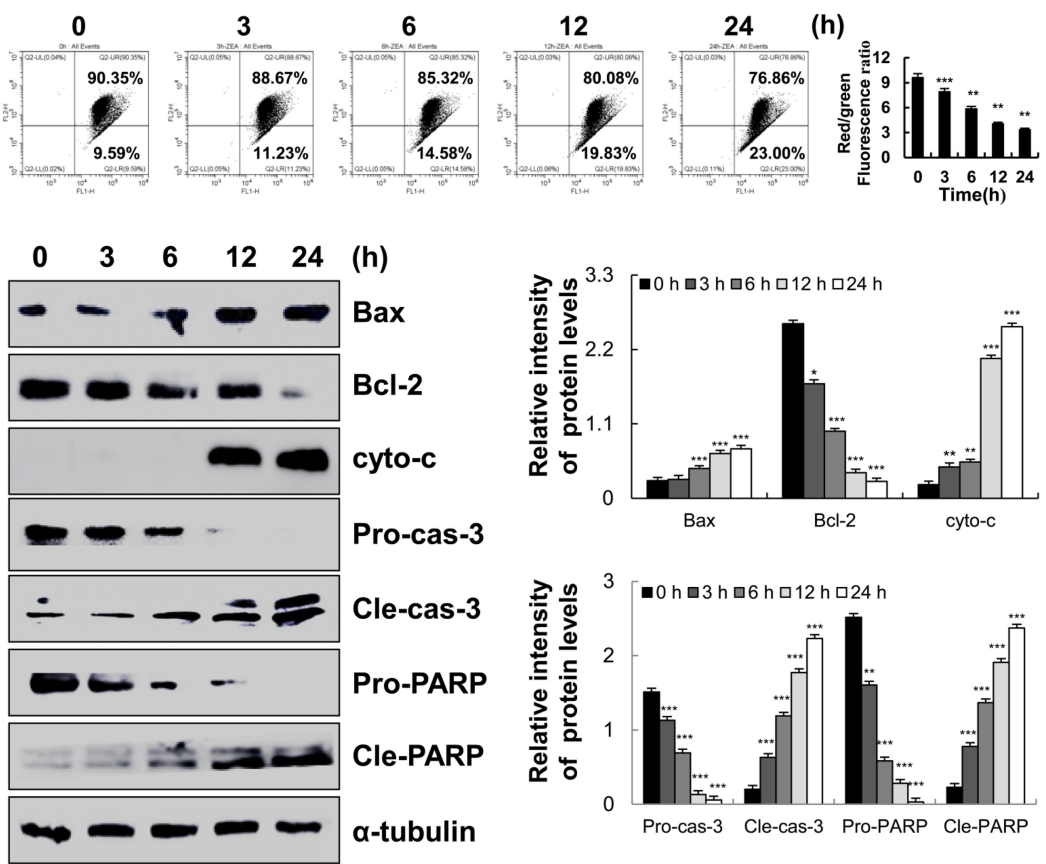

Figure 2 Apoptotic effect of zeaxanthin on AGS cells. (A) AGS cells were treated with $17 \mu$ M zeaxanthin for 3, 6, I2, and 24 h and incubated with Hoechst $33342 / P I$. The fluorescence intensities and morphological changes in cells were observed under a fluorescence microscope (original magnification, $\times 200)$. (B) AGS cells were stained with Annexin V-FITC/PI solution and analysed by flow cytometry. (C) AGS cells were stained with JC-I reagent and analysed by flow cytometry. (D) The protein expression levels were measured by Western blot analysis following treatment of AGS cells with zeaxanthin; $\alpha$-tubulin was used as an internal control. $*_{p}<0.05$, $* * p<0.0 \mathrm{I}$, **** $<<0.00 \mathrm{I}$ vs $0 \mathrm{~h}$. 

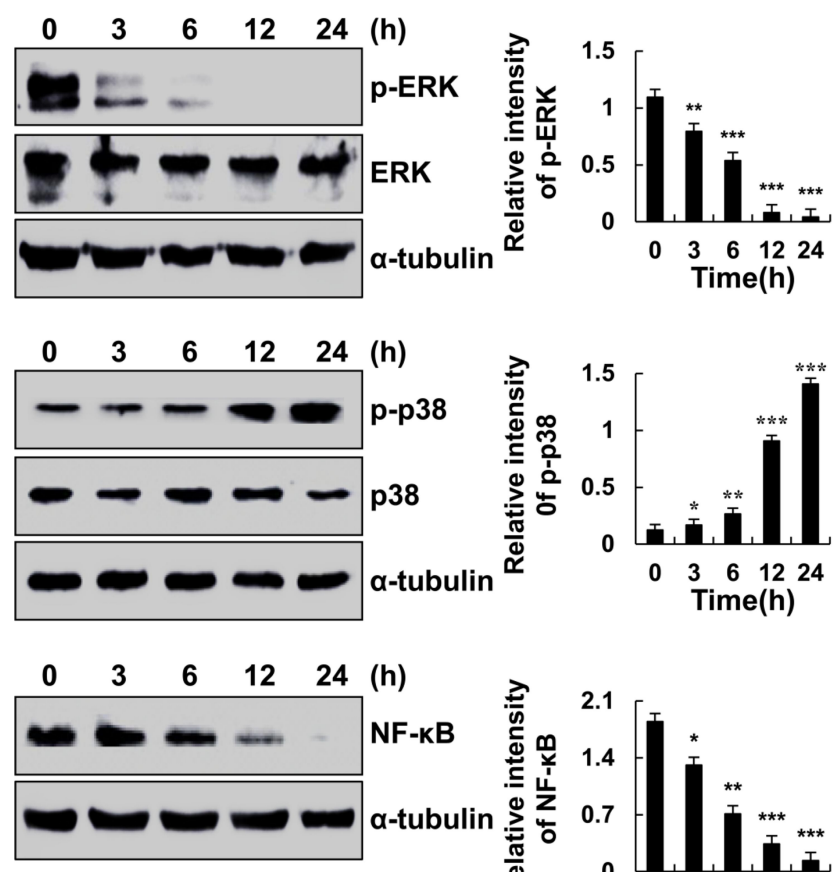
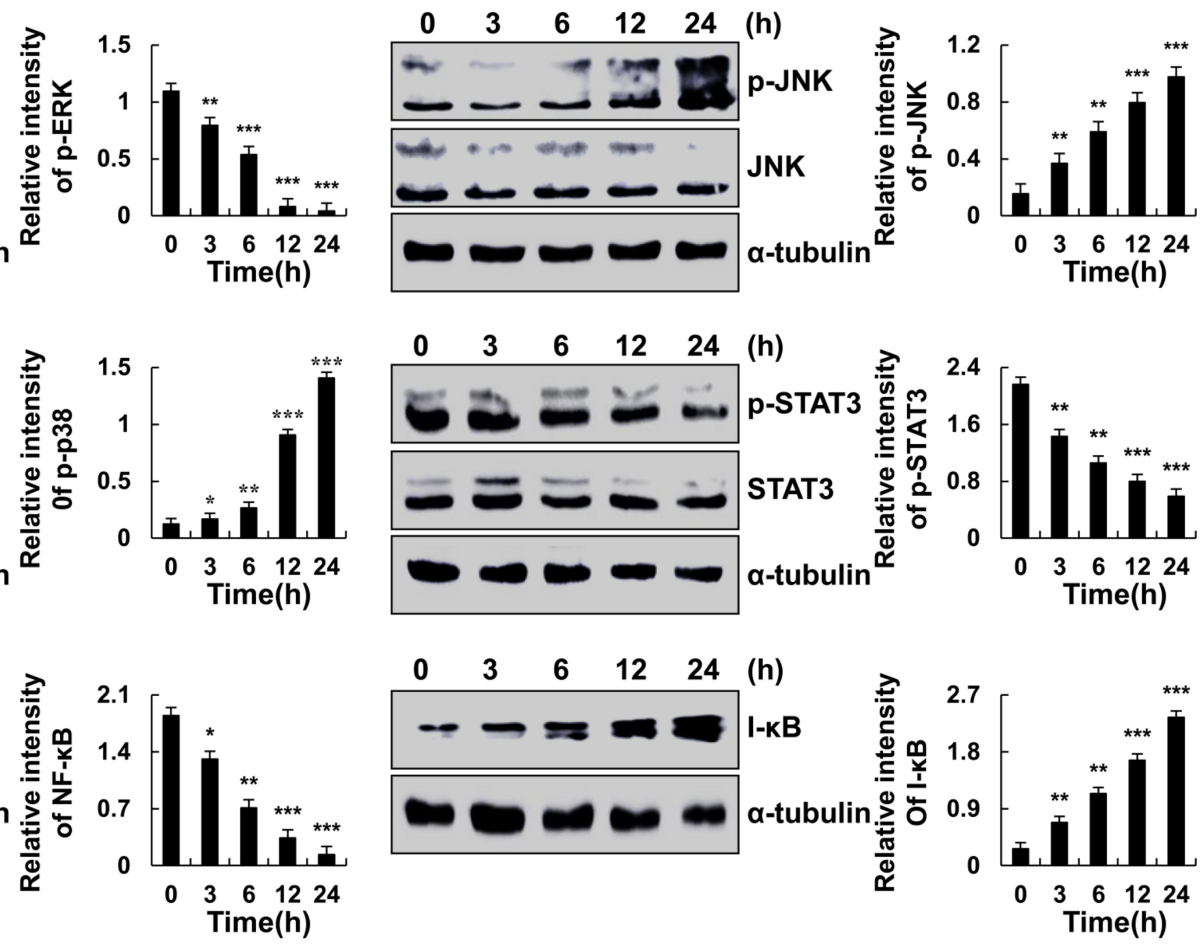

Figure 3 Zeaxanthin induces AGS cell apoptosis through the MAPK, STAT3, and NF- $\kappa B$ signaling pathways. AGS cells were treated with zeaxanthin for 3 , 6, I2, and 24 h.

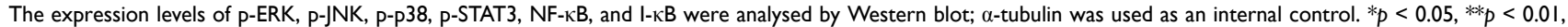
$* * * p<0.00 \mathrm{I}$ vs $0 \mathrm{~h}$.

zeaxanthin and SB203580 groups significantly reduced, while the protein expression levels of p-STAT3, NF- $\mathrm{kB}$, and pro-cas-3 significantly increased. Compared with the untreated group, the protein expression levels of I- $\mathrm{KB}, \mathrm{Bcl}-$ 2 , and cle-cas-3 in the SP600125 group significantly reduced, while the protein expression levels of p-JNK, p-STAT3, NF- $\mathrm{BB}$, and pro-cas-3 significantly increased. Compared with the untreated group, the protein expression

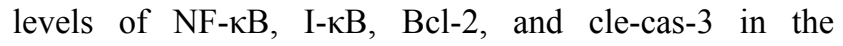
SB203580 group significantly reduced, while the protein expression levels of p-p38, p-STAT3, and pro-cas-3 significantly increased.

\section{Zeaxanthin Induces ROS Generation in AGS Cells}

As shown in Figure 5A, under the action of zeaxanthin, the GES-1 intracellular ROS level decreased from $49.43 \%$ to $32.03 \%$ as the treatment time increased. As shown in Figure 5B, under the action of zeaxanthin, the AGS intracellular ROS level increased from $50.78 \%$ to $78.63 \%$ as the treatment time increased. As shown in Figure 5C, under the action of zeaxanthin, the AGS intracellular ROS level increased from $51.96 \%$ to $82.25 \%$ as concentration increased. However, after the addition of NAC
(ROS inhibitor), the ROS content in the cells was suppressed (Figure 5D). To further explore the role of ROS in apoptosis, Western blot analysis was performed on the cells after the addition of NAC. As shown in Figure 5E, compared with the untreated group, the protein expression levels of p-ERK, p-STAT3, NF- $\kappa$ B, pro-cas-3 and proPARP in the zeaxanthin groups significantly reduced, while the protein expression levels of p-p38, p-JNK, $\mathrm{I}-\kappa \mathrm{B}$, cle-cas-3, and cle-PARP significantly increased.

\section{Zeaxanthin Induces Cell Cycle Arrest in AGS Cells}

As shown in Figure 6A, zeaxanthin arrested AGS cells at the $\mathrm{G} 2 / \mathrm{M}$ phase, and the cell distribution increased from $24.28 \%$ to $37.00 \%$. As shown in Figure $6 \mathrm{~B}$, the protein expression levels of p-AKT, CDK1/2, Cyclin A, and Cyclin B1 decreased, while the protein expression levels of $\mathrm{p} 21$ and p27 increased. To further explore the role of ROS in the cell cycle, Western blot analysis was performed on the cells after the addition of NAC. As shown in Figure 6C, Compared with the untreated group, the protein expression levels of p-AKT, CDK1/2, Cyclin A, and Cyclin B1 in the zeaxanthin group significantly reduced, while the protein expression levels of p21 and p27 significantly increased. Compared with the 

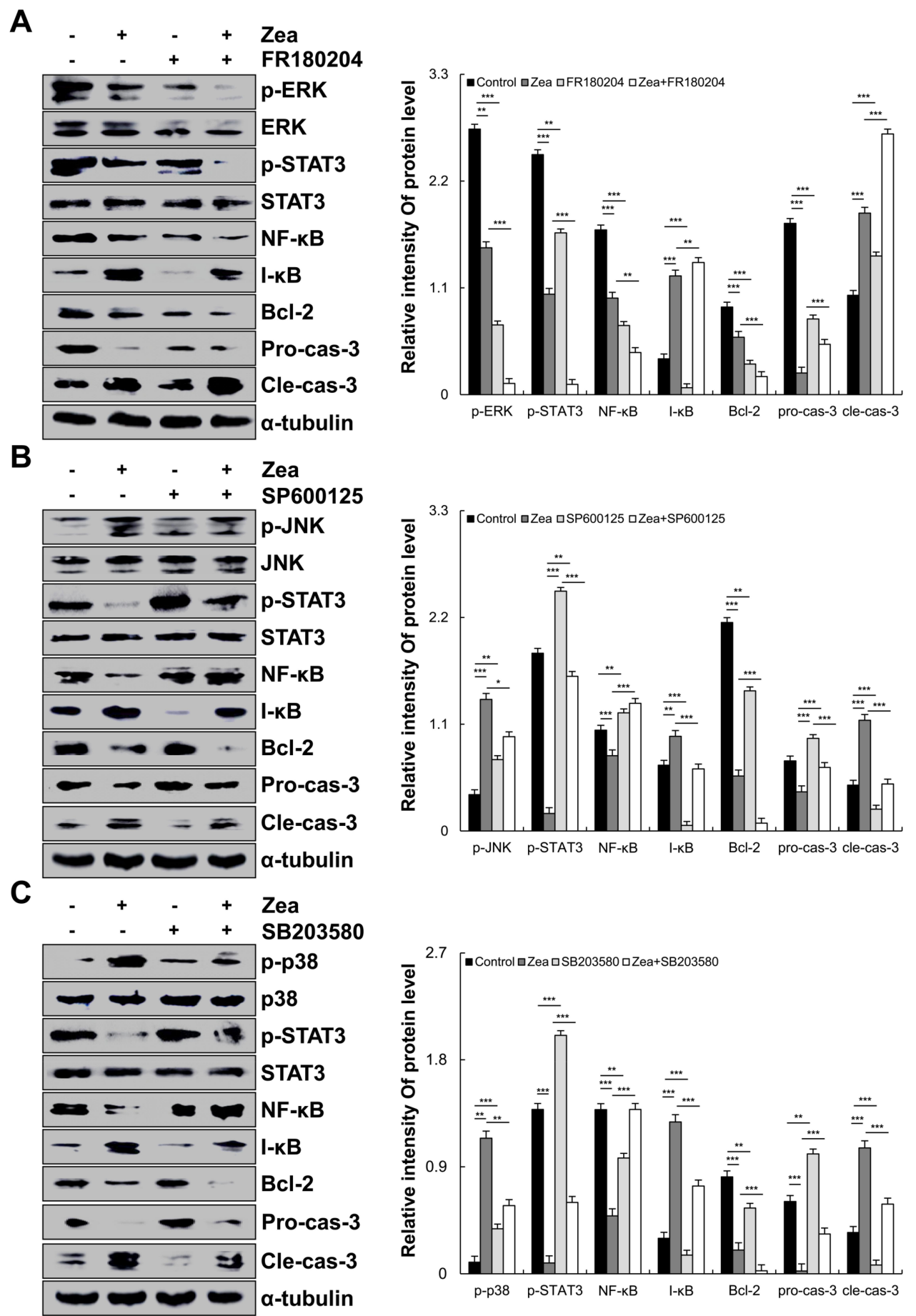

Figure 4 Effects of zeaxanthin on the MAPK, STAT3, and NF-kB signaling pathways in AGS cells. (A) Expression levels of p-ERK, p-STAT3, NF- $\mathrm{kB}$ I-kB, Bcl-2, pro-cas-3, and cle-cas-3 after the addition of zeaxanthin and FRI80204 (ERK inhibitor). (B) Expression levels of p-JNK, P-STAT3, NF-KB I-KB, Bcl-2, pro-cas-3, and cle-cas-3 after the addition of zeaxanthin and SP600I 25 (JNK inhibitor). (C) Expression levels of p38, p-STAT3, NF-kB, I-kB, Bcl-2, pro-cas-3, and cle-cas-3 after the addition of zeaxanthin and SB203580 ( $\mathrm{p} 38$ inhibitor); $\alpha$-tubulin was used as an internal control. $* p<0.05, * * p<0.01$, $* * * p<0.001$ vs zeaxanthin + MAPK inhibitor.

zeaxanthin group, the protein expression levels of p-AKT, CDK1/2, Cyclin A, and Cyclin B1 in the zeaxanthin and NAC groups significantly increased, while the protein expression levels of p21 and p27 significantly reduced. There was no significant difference in protein expression levels between the untreated group and the NAC group. Taken together, these results indicate that zeaxanthin regulates MAPK, AKT, STAT3 and NF-KB signaling pathways by mediating ROS levels in AGS cells, and induces G2/M cell cycle arrest and apoptosis (Figure 7). 
A

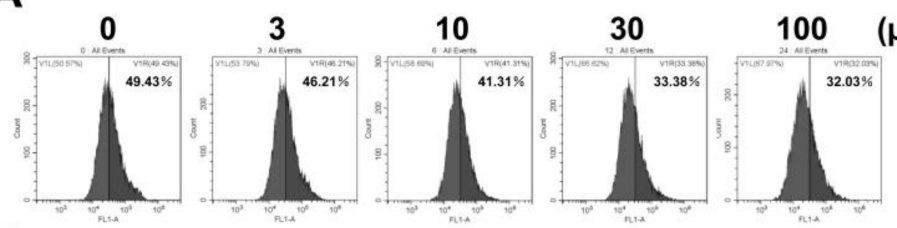

B
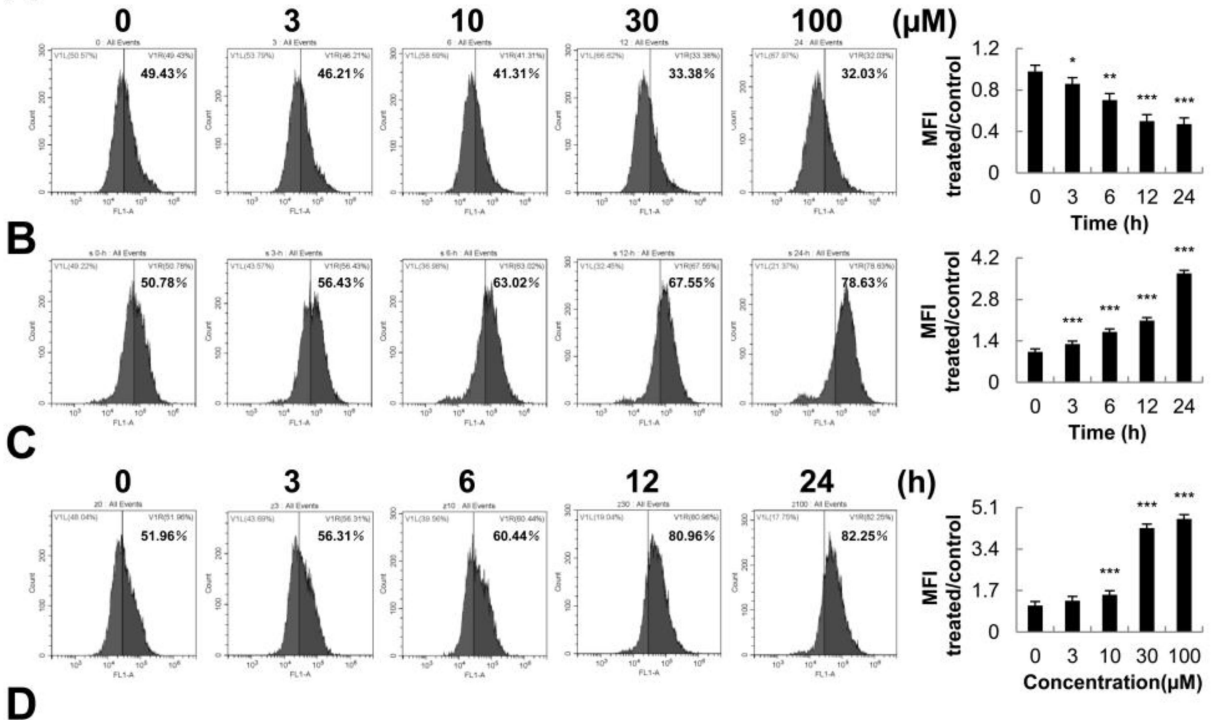

3

6

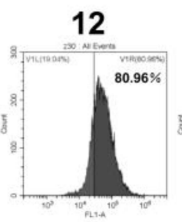

$24(h)$
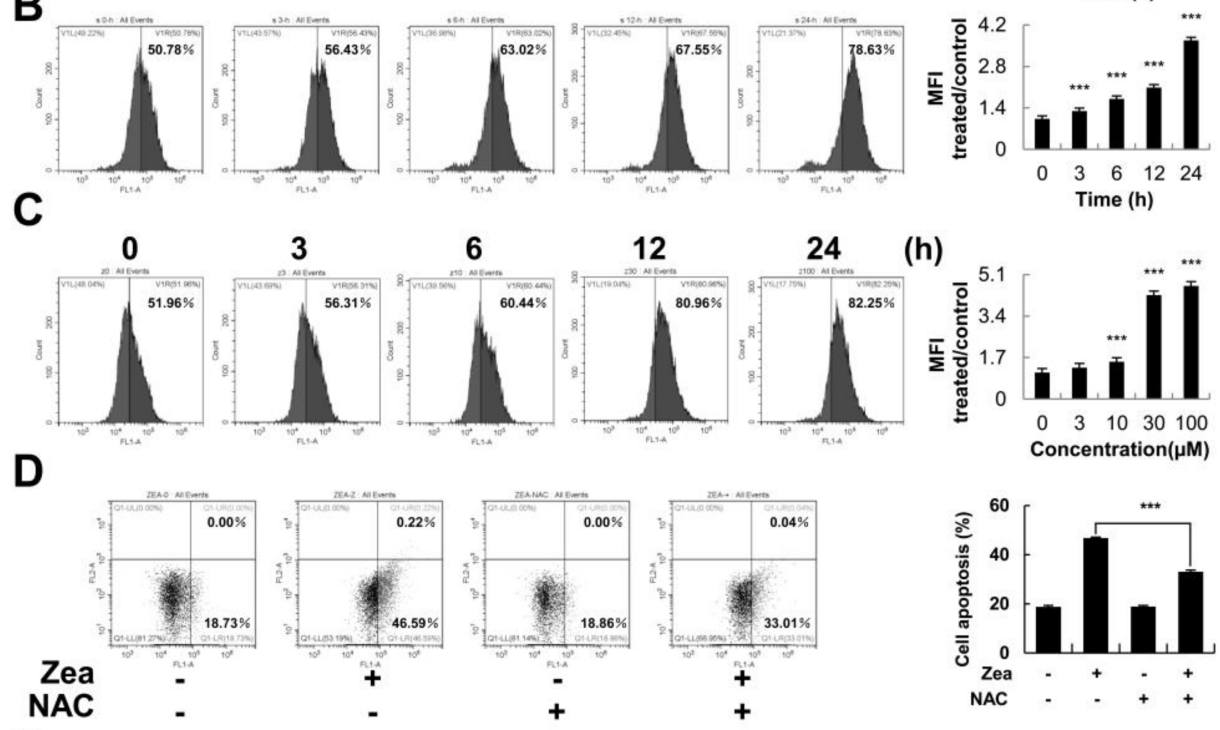

E

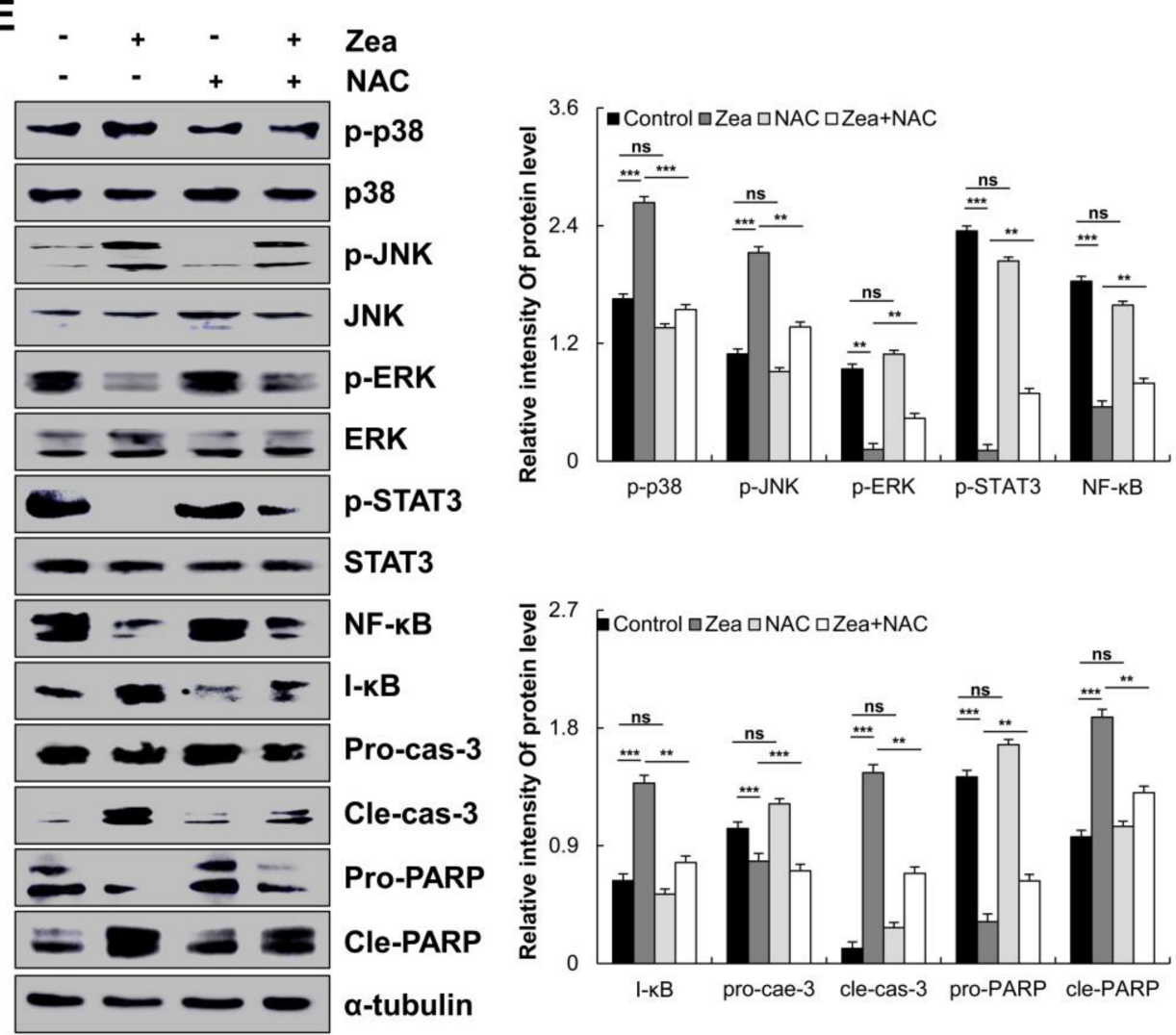

Figure 5 Promoting effects of zeaxanthin on ROS generation and the induction of apoptosis in AGS cells (A) GES-I cells were treated with zeaxanthin for $3,6,12$, and $24 \mathrm{~h}$, and the intracellular ROS content was detected. (B) AGS cells were treated with zeaxanthin for 3, 6, 12, and $24 \mathrm{~h}$, and the intracellular ROS content was detected. (C) AGS cells were treated with zeaxanthin at concentrations of 3, 10, 30, and $100 \mu \mathrm{M}$ for $24 \mathrm{~h}$, and the intracellular ROS content was detected. (C) AGS cells were treated with zeaxanthin for 3, 6, 12, and $24 \mathrm{~h}$, and the intracellular ROS content was detected. (D) AGS cells were treated with NAC and zeaxanthin, and the intracellular ROS content was detected. (E) AGS cells were treated with zeaxanthin and NAC, after which the expression levels of MAPKs, STAT3, NF-kB, l-kB, pro-cas-3, cle-cas-3, pro-PARP, and cle-PARP were detected by Western blot analysis; $\alpha$-tubulin was used as internal control. ${ }^{*} p<0.05, * * p<0.01, * * *<0.001$ vs the NAC + zeaxanthin group. 
A

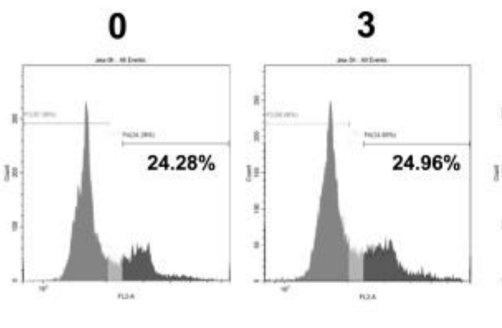

6

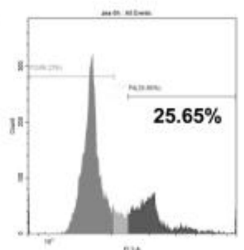

12

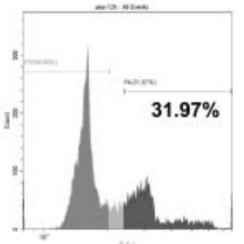

24

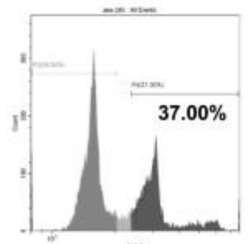

(h)

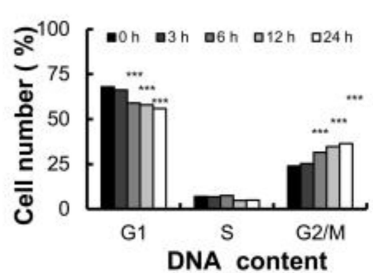

B
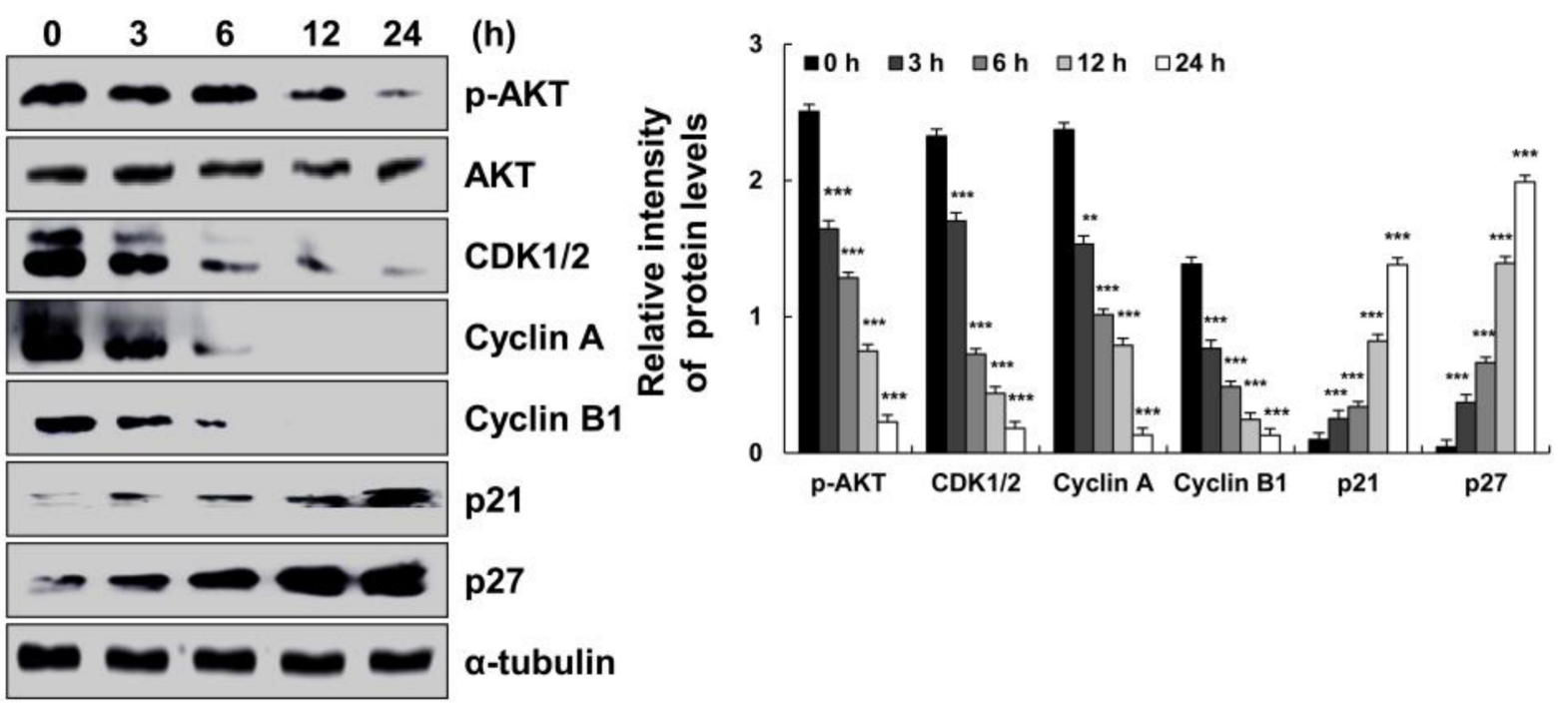

C
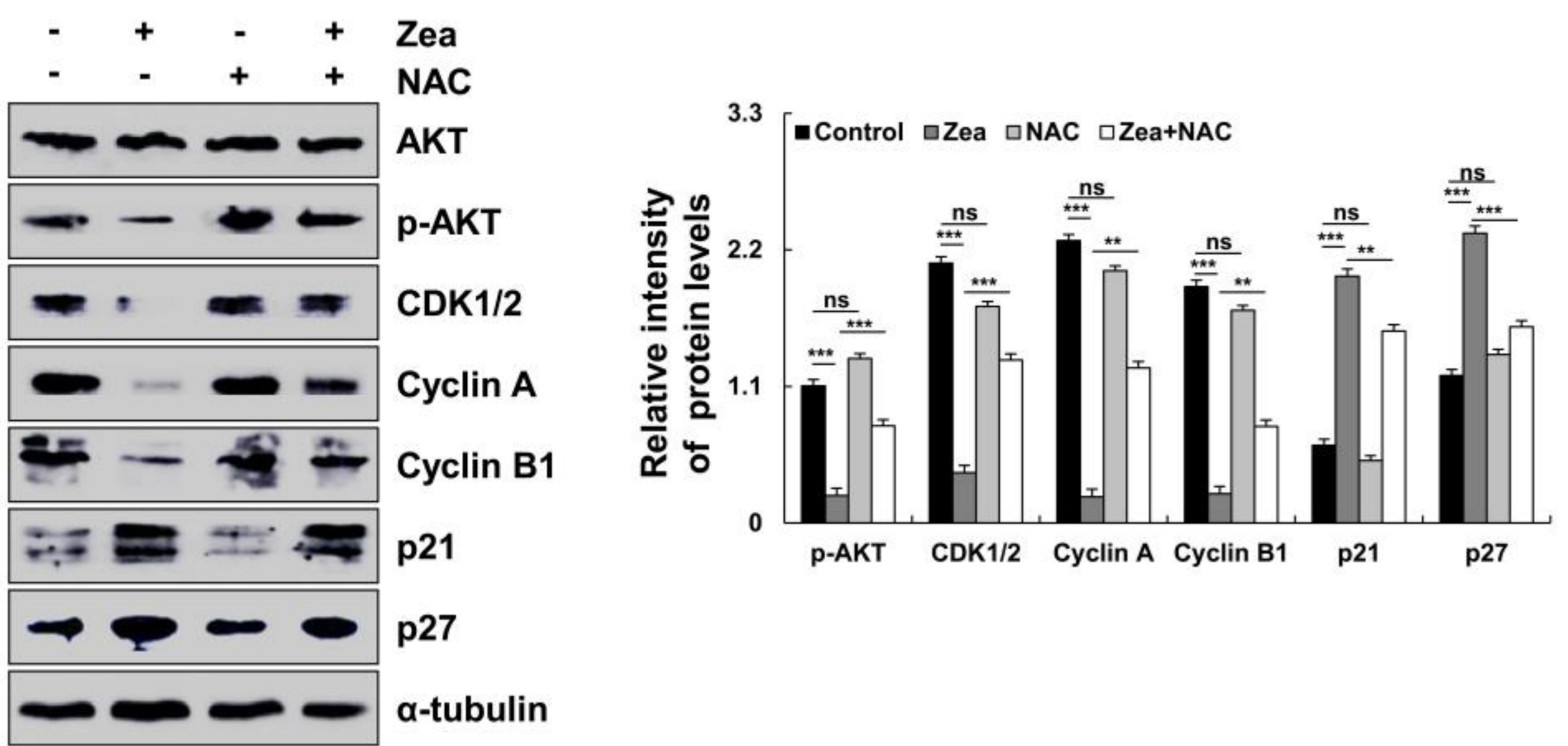

Figure 6 The effect of zeaxanthin on cell cycle and cell cycle-related protein expression levels in AGS cells. (A) AGS cells were treated with I7 $\mu$ M zeaxanthin for 3, 6, 12 , and $24 \mathrm{~h}$, and the cell cycle distribution was analysed by flow cytometry. (B) After treatment with $17 \mu \mathrm{M}$ zeaxanthin for 3, 6, 12 and $24 \mathrm{~h}$, the expression levels of G2/Mrelated cyclin, p-AKT, CDKI/2, Cyclin A, Cyclin BI, p2I, and p27 were analysed by Western blotting. (C) AGS cells were treated with NAC and zeaxanthin, and the expression levels of G2/M-related cyclin, p2I, p27, Cyclin BI, A, CDKI/2, and p-AKT were analysed by Western blotting; $\alpha$-tubulin was used as an internal control. **p < $0.01, * * * p<0.001$ vs the NAC + zeaxanthin group.

\section{Discussion}

Zeaxanthin, a carotenoid, has potential anticancer effects. ${ }^{20}$

The results of CCK-8 analysis show that zeaxanthin effectively kills human gastric cancer cells and has low toxicity in normal human cells compared with that of 5FU. Out of 12 human gastric cancer cell lines, AGS cells 


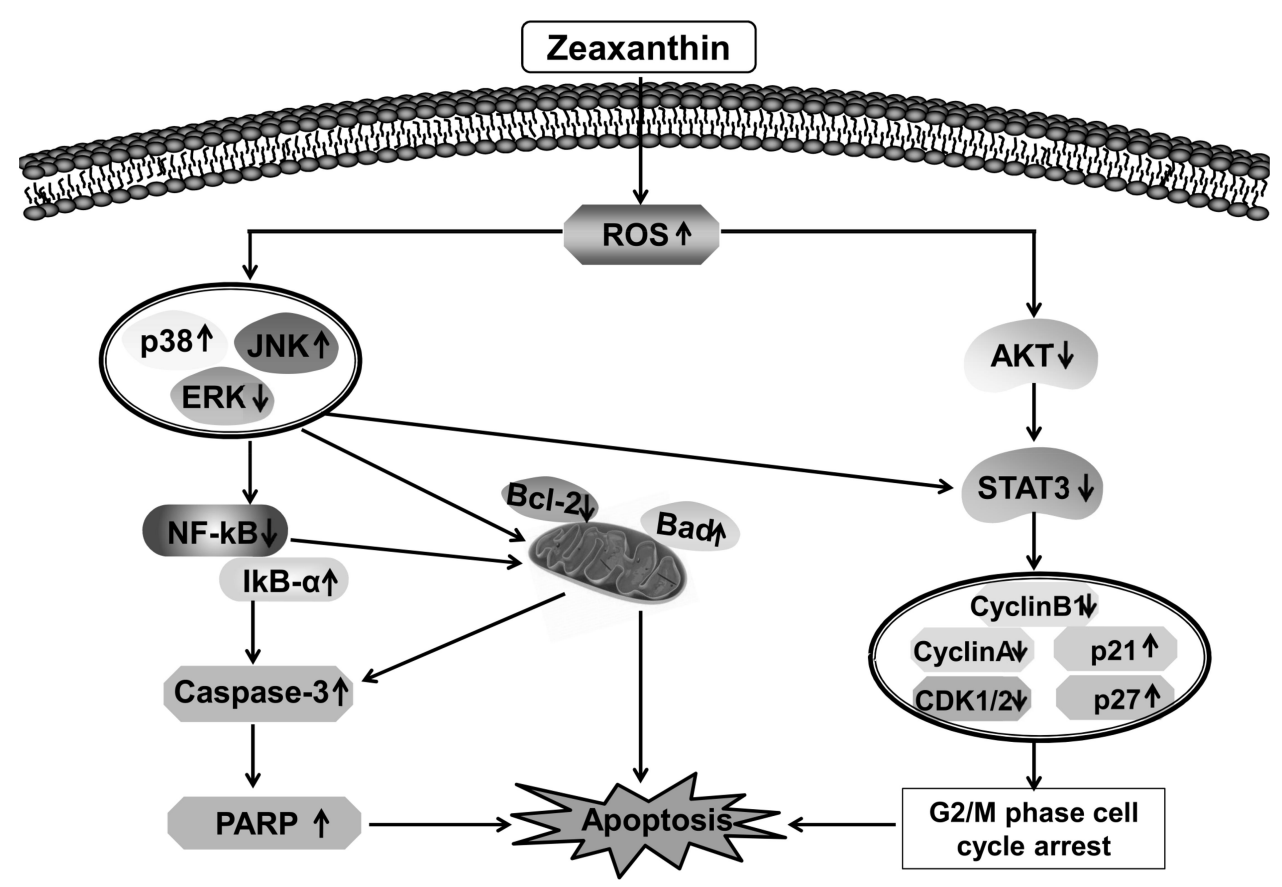

Figure 7 Schematic illustration of the underlying mechanisms of zeaxanthin's effects on signaling pathways and the induction of apoptosis in human gastric cancer cells. The mechanism of zeaxanthin anti-cancer activity as related to the MAPK, AKT, STAT3, and NF-KB signaling pathways.

were the most sensitive to zeaxanthin, with an $\mathrm{IC}_{50}$ value of $17 \mu \mathrm{M}$. Based on the results of CCK-8 analysis, the signal transduction pathways of zeaxanthin and the production of ROS in human gastric cancer cells were further studied.

Previous studies have shown that the two main apoptotic pathways of cells are the death receptor pathway and the mitochondrial-related pathway. ${ }^{33}$ In the presence of high concentrations of ROS, MMP decreases, cytochrome $\mathrm{C}$ is released and transferred to the cytoplasm, related apoptotic factors (such as Bax protein) are regulated, and the caspase cascade is initiated. ${ }^{34-36}$ PARP is a DNA repair enzyme. Under the action of caspase-3, PARP is cleaved and loses its enzymatic activity, thereby accelerating cell instability. ${ }^{37}$ The present study revealed that under the action of zeaxanthin, the expression levels of cytochrome $\mathrm{C}$ protein and the pro-apoptotic protein Bax increased, while the expression levels of the anti-apoptotic protein Bcl-2 decreased. In addition, cle-cas-3 and cle-PARP protein expression levels increased significantly after zeaxanthin treatment. These results indicate that zeaxanthin promotes cell apoptosis through the mitochondrial pathway.

The regulation of intracellular ROS is an important factor in apoptosis. Increased intracellular ROS levels can induce apoptosis by regulating the MAPK pathway. ${ }^{38-40}$ After consulting a large amount of literature, we found that zeaxanthin can indeed reduce the formation of ROS in normal cells, but it can also induce the generation of ROS in cancer cells. ${ }^{41-43}$ Therefore, we detected the ROS content in human normal GES-1 cells and human gastric cancer AGS cells after zeaxanthin. The results show that zeaxanthin can effectively inhibit the level of ROS in GES- 1 cells and induce an increase in the level of ROS in AGS cells. The inhibitory effect of zeaxanthin on ROS in normal cells is consistent with other reports. Zeaxanthin induces the production of ROS when it acts on gastric cancer cells, which is contrary to the results of normal cells. This may be the result of different signal pathways and will be studied in the future. In addition, NAC inhibited the increase in reactive oxygen content, but when zeaxanthin and NAC acted upon AGS cells at the same time, the intracellular reactive oxygen content increased. MAPKs, including ERK, JNK, and p38, are involved in cell proliferation, differentiation, or apoptosis, depending on cell type and stimulation. ${ }^{44}$ Studies have shown that ROS mediates apoptosis of human melanoma A375 cells through the MAPK pathways. ${ }^{30}$ In addition, our results revealed that the protein expression levels of p-STAT3 and NF- $\mathrm{kB}$ changed after the treatment of cells with FR180204, SP600125, and SB203580 inhibitors. In other words, zeaxanthin can regulate the MAPK, NF- $\mathrm{kB}$, and STAT3 pathways by regulating intracellular ROS, thereby inducing cell apoptosis.

Cancer cells proliferate after receiving mitotic signals. If cells are blocked at a certain stage of the proliferation cycle, their proliferation is inhibited. The cell cycle is divided as the 
G0/G1 phase, S phase, and G2/M phase. In the present study, flow cytometry was used to investigate the cell blocking effect of zeaxanthin in the G2/M phase of AGS cells. In a previous study, it was found that astaxanthin, a carotenoid, induces G2/ $\mathrm{M}$ cell cycle arrest by downregulating the expression level of Cyclin B1. ${ }^{45}$ This is consistent with our results when further verified by Western blot analysis. Studies have shown that p27 and $\mathrm{p} 21$ proteins significantly increase in a time-dependent manner, while p-AKT, CDK1/2, Cyclin A, and Cyclin B1 significantly decrease. With the addition of NAC inhibitors, the increase in $\mathrm{p} 27$ and $\mathrm{p} 21$ protein expression levels and the decrease of p-AKT, CDK1/2, Cyclin A, and CynlinB1 protein expression levels was suppressed. This indicates that as the ROS content increases, the AKT pathway blocks cells at the $\mathrm{G} 2 / \mathrm{M}$ phase and causes apoptosis under the regulation of ROS.

\section{Conclusion}

Zeaxanthin induces G2/M cell cycle arrest and induces apoptosis in AGS cells by up-regulating intracellular ROS levels, and regulating the MAPK, AKT, STAT3, and NF-KB signaling pathways. Zeaxanthin, a natural medicine, is expected to be useful for the treatment of gastric cancer.

\section{Funding}

This work was supported by the Postdoctoral Scientific Research Foundation of Heilongjiang Province of China under Grant (LBH-Q13132), the Heilongjiang Farms \& Land Reclamation Administration Support Project for Key Scientific Research (HKKYZD190705), the Heilongjiang Bayi Agricultural University Support Program for 'San Zong' (TDJH201905), Heilongjiang Touyan Innovation Team Program (2019HTY078), Research Project of Heilongjiang Bayi Agricultural University (XDB202012), Heilongjiang Bayi Agricultural University Graduate Innovation Research Project (YJSCX2019-Y55), Heilongjiang Province College Student Innovation and Entrepreneurship Training Program Project (202010223001), and Heilongiiang Province College Student Innovation and Entrepreneurship Training Program Project (202010223004).

\section{Disclosure}

The authors report no conflicts of interest in this work.

\section{References}

1. Song Z, Wu Y, Yang J, et al. Progress in the treatment of advanced gastric cancer. Tumor Biol. 2017;39(7):101042831771462. doi:10. $1177 / 1010428317714626$
2. Bray F, Ferlay J, Soerjomataram I, et al. Global cancer statistics 2018: GLOBOCAN estimates of incidence and mortality worldwide for 36 cancers in 185 countries. CA Cancer J Clin. 2018;68(6):394-424.

3. Malfertheiner P. Helicobacter pylori treatment for gastric cancer prevention. $N$ Engl J Med. 2018;378(12):1154-1156. doi:10.1056/ NEJMe 1800147

4. Hengartner MO. The biochemistry of apoptosis. Nature. 2000;407 (6805):770-776. doi:10.1038/35037710

5. Thornberry NA, Rano TA, Peterson EP, et al. A combinatorial approach defines specificities of members of the caspase family and granzyme B: functional relationships established for key mediators of apoptosis. J Biol Chem. 1997;272(29):17907-17911. doi:10.1074/ jbc.272.29.17907

6. White E. Life, death, and the pursuit of apoptosis. Genes Dev. 1996;10(1):1-15. doi:10.1101/gad.10.1.1

7. Cao XH, Wang AH, Wang CL, et al. Surfactin induces apoptosis in human breast cancer MCF-7 cells through a ROS/JNK-mediated mitochondrial/caspase pathway. Chem Biol Interact. 2010;183 (3):357-362. doi:10.1016/j.cbi.2009.11.027

8. Reuter S, Eifes S, Dicato M, et al. Modulation of anti-apoptotic and survival pathways by curcumin as a strategy to induce apoptosis in cancer cells. Biochem Pharmacol. 2008;76(11):1340-1351. doi:10.1016/j.bcp.2008.07.031

9. Sikka S, Sethi G. Anticancer effects of agents derived from fruits and vegetables against stomach cancer. Anticancer Prop Fruits Veg. 2015;12(02):309-335.

10. Kuo L-M, Chen P-J, Sung P-J, et al. The bioactive extract of pinnigorgia sp. induces apoptosis of hepatic stellate cells via ROS-ERK/ JNK-Caspase-3 signaling. Mar Drugs. 2018;16(1):19. doi:10.3390/ md16010019

11. Jiang D-J, Jia S-J, Dai Z, et al. Asymmetric dimethylarginine induces apoptosis via p38 MAPK/caspase-3-dependent signaling pathway in endothelial cells. $J$ Mol Cell Cardiol. 2006;40(4):529-539. doi:10.1016/j.yjmcc.2006.01.021

12. Wang K, Chen B, Yin T, et al. N-methylparoxetine blocked autophagic flux and induced apoptosis by activating ROS-MAPK pathway in non-small cell lung cancer cells. Int J Mol Ences. 2019;20(14):3415.

13. Hoefen RJ, Berk BC. The role of MAP kinases in endothelial activation. Vascul Pharmacol. 2002;38:271-273. doi:10.1016/S1537-1891 (02)00251-3

14. Chappell WH, Steelman LS, Long JM, et al. Ras/Raf/MEK/ERK and $\mathrm{PI} 3 \mathrm{~K} / \mathrm{PTEN} / \mathrm{Akt} / \mathrm{mTOR}$ inhibitors: rationale and importance to inhibiting these pathways in human health. Oncotarget. 2011;2(3):135164. doi:10.18632/oncotarget.240

15. Krasilnikov M, Ivanov VN, Dong J, et al. ERK and PI3K negatively regulate STAT-transcriptional activities in human melanoma cells: implications towards sensitization to apoptosis. Oncogene. 2003;22 (26):4092-4101. doi:10.1038/sj.onc. 1206598

16. Poage M, Le Martret B, Jansen MAK, et al. Modification of reactive oxygen species scavenging capacity of chloroplasts through plastid transformation. Plant Mol Biol. 2011;76(3-5):371-384. doi:10.1007/ s11103-011-9784-y

17. Sakon S, Xue X, Takekawa M, et al. NF-kappaB inhibits TNFinduced accumulation of ROS that mediate prolonged MAPK activation and necrotic cell death. EMBO J. 2003;22(15):3898-3909. doi:10.1093/emboj/cdg379

18. Yip NC, Fombon IS, Liu P, et al. Disulfiram modulated ROS-MAPK and NFKB pathways and targeted breast cancer cells with cancer stem cell-like properties. $B r \quad J$ Cancer. 2011;104(10):1564-1574. doi:10.1038/bjc.2011.126

19. Maccarrone M, Bari M, Gasperi V, et al. The photoreceptor protector zeaxanthin induces cell death in neuroblastoma cells. Anticancer Res. 2005;25(6B):3871-3876.

20. Abdel-Aal El SM, Akhtar H, Zaheer K, et al. Dietary sources of lutein and zeaxanthin carotenoids and their role in eye health. Nutrients. 2013;5(4):1169-1185. doi:10.3390/nu5041169 
21. Firdous AP, Kuttan G, Kuttan R. Anti-inflammatory potential of carotenoid meso-zeaxanthin and its mode of action. Pharm Biol. 2015;53(7):691-697.

22. Bi MC, Rosen R, Zha RY, et al. Zeaxanthin induces apoptosis in human uveal melanoma cells through Bcl-2 family proteins and intrinsic apoptosis pathway. Evid Based Complement Alternat Med. 2013;2013:205082. doi:10.1155/2013/205082

23. Jeurnink SM, Ros MM, Leenders M, et al. Plasma carotenoids, vitamin $\mathrm{C}$, retinol and tocopherols levels and pancreatic cancer risk within the European Prospective Investigation into Cancer and Nutrition: a nested case-control study: plasma micronutrients and pancreatic cancer risk. Int $J$ Cancer. 2015;136(6):E665-E676. doi:10.1002/ijc. 29175

24. Yan B, Min-Shan L, Wang L, et al. Specific serum carotenoids are inversely associated with breast cancer risk among Chinese women: a case-control study. Br J Nutri. 2016;115(01):129-137. doi:10.1017/ S000711451500416X

25. Wu S, Liu Y, Michalek JE, et al. Carotenoid intake and circulating carotenoids are inversely associated with the risk of bladder cancer: a dose-response meta-analysis. Adv Nutr. 2020;11(3):630-643. doi:10.1093/advances/nmz120

26. Goswami S, Srivastava A, Pushker N, et al. Abstract 3812: induction of apoptosis by zeaxanthin in human uveal melanoma cells. Cancer Res. 2015;75(15 Supplement):3812.

27. Wang JR, Luo YH, Piao XJ, et al. Mechanisms underlying isoliquiritigenin-induced apoptosis and cell cycle arrest via ROS-mediated MAPK/STAT3/NF- $\kappa$ B pathways in human hepatocellular carcinoma cells. Drug Dev Res. 2019;80(4):461-470. doi:10.1002/ddr.21518

28. Zhang Y, Luo YH, Piao XJ, et al. The design of 1,4-naphthoquinone derivatives and mechanisms underlying apoptosis induction through ROS-dependent MAPK/Akt/STAT3 pathways in human lung cancer cells. Bioorg Med Chem. 2019;27(8):1577-1587. doi:10.1016/j. bmc.2019.03.002

29. Zang YQ, Feng YY, Luo YH, et al. Glycitein induces reactive oxygen species-dependent apoptosis and G0/G1 cell cycle arrest through the MAPK/STAT3/NF-кB pathway in human gastric cancer cells. Drug Dev Res. 2019;80(5):573-584.

30. Luo YH, Li JQ, Zhang Y, et al. Quinalizarin induces cycle arrest and apoptosis via reactive oxygen species-mediated signaling pathways in human melanoma A375 cells. Drug Dev Res. 2019;80(8):1040-1050. doi: $10.1002 /$ ddr.21582

31. Wang JR, Shen GN, Luo YH, et al. The compound 2-(naphthalene-2thio)-5,8-dimethoxy-1,4-naphthoquinone induces apoptosis via reactive oxygen species-regulated mitogen-activated protein kinase, protein kinase B, and signal transducer and activator of transcription 3 signaling in human gastric cancer cells. Drug Dev Res. 2018;79 (6):295-306

32. Wang H, Luo YH, Shen GN, et al. Two novel 1,4-naphthoquinone derivatives induce human gastric cancer cell apoptosis and cell cycle arrest by regulating reactive oxygen species-mediated MAPK/Akt/ STAT3 signaling pathways. Mol Med Rep. 2019;20(3):2571-2582.
33. Wang X. The expanding role of mitochondria in apoptosis. Genes Dev. 2001;15(22):2922-2933.

34. Crompton M, Barksby E, Johnson N, et al. Mitochondrial intermembrane junctional complexes and their involvement in cell death. Biochimie (Paris). 2002;84(2-3):143-152. doi:10.1016/S0300-9084 (02)01368-8

35. Chipuk JE, Bouchier-Hayes L, Green DR. Mitochondrial outer membrane permeabilization during apoptosis: the innocent bystander scenario. Cell Death Differ. 2006;13(8):1396-1402. doi:10.1038/sj. cdd.4401963

36. Chang IC, Huang YJ, Chiang TI, et al. Shikonin induces apoptosis through reactive oxygen species/extracellular signal-regulated kinase pathway in osteosarcoma cells. Biol Pharm Bull. 2010;33(5):816824. doi:10.1248/bpb.33.816

37. Haffner MC, De Marzo AM, Meeker AK, et al. Transcriptioninduced DNA double strand breaks: both oncogenic force and potential therapeutic target? Clin Cancer Res. 2011;17(12):3858-3864. doi:10.1158/1078-0432.CCR-10-2044

38. Wang K, Chu D, Wu J. et al. Cinobufagin induced cell apoptosis and protective autophagy through the ROS/MAPK signaling pathway. Life Sci;2019. 116642. doi:10.1016/j.1fs.2019.116642

39. Wang K, Chen B, Yin T, et al. N-methylparoxetine blocked autophagic flux and induced apoptosis by activating ROS-MAPK pathway in non-small cell lung cancer cells. Int J Mol Sci. 2019;20(14):3415. doi:10.3390/ijms20143415

40. Liu YN, Fan DD. Ginsenoside Rg5 induces G2/M phase arrest, apoptosis and autophagy via regulating ROS-mediated MAPK pathways against human gastric cancer. Biochem Pharmacol. 2019;168:285-304. doi:10.1016/j.bcp.2019.07.008

41. Ying C, Chen L, Wang S, et al. Zeaxanthin ameliorates high glucoseinduced mesangial cell apoptosis through inhibiting oxidative stress via activating AKT signaling-pathway. Biomedicine \& Pharmacotherapy. 2017;90:796-805. doi:10.1016/j.biopha.2017.04.013

42. Liu M, Zheng M, Cai D, et al. Zeaxanthin promotes mitochondrial biogenesis and adipocyte browning via AMPK $\alpha 1$ activation. Food Funct. 2019;10(4):2221-2233. doi:10.1039/C8FO02527D

43. Rapp LM, Maple SS, Choi JH. Lutein and zeaxanthin concentrations in rod outer segment membranes from perifoveal and peripheral human retina. Invest Ophthalmol Vis Sci. 2000;41(5):1200-1209.

44. Hui KF, Yeung PL, Chiang AK. Induction of MAPK- and ROSdependent autophagy and apoptosis in gastric carcinoma by combination of romidepsin and bortezomib. Oncotarget. 2016;7(4):44544467. doi:10.18632/oncotarget.6601

45. Qian X, Tan C, Yang B, et al. Astaxanthin increases radiosensitivity in esophageal squamous cell carcinoma through inducing apoptosis and G2/M arrest. Dis Esophagus. 2017;30(6):1-7. doi:10.1093/dote/ $\operatorname{dox} 027$
OncoTargets and Therapy

\section{Publish your work in this journal}

OncoTargets and Therapy is an international, peer-reviewed, open access journal focusing on the pathological basis of all cancers, potential targets for therapy and treatment protocols employed to improve the management of cancer patients. The journal also focuses on the impact of management programs and new therapeutic agents and protocols on patient perspectives such as quality of life, adherence and satisfaction. The manuscript management system is completely online and includes a very quick and fair peer-review system, which is all easy to use. Visit http://www.dovepress.com/ testimonials.php to read real quotes from published authors. 